\title{
Tinto's Construct of Academic Motivation, Integration and Performance - A Case From Turkey
}

\author{
Yaman Köseoğlu \\ Lecturer; Faculty of Arts and Sciences, Bahçeşehir University, İstanbul, Turkey
}

\begin{abstract}
The indirect effects of seven types of academic motivation on academic performances of 258 first year university students when mediated by academic integration are investigated. When these seven types were examined jointly in the statistical model used, it was found that academic integration mediated only the relationship between the intrinsic motivation to accomplish things and the first year grade point average. This suggests that students who attend university targeting a successful educational life may infer that the university is fostering their cognitive powers and academically they may exhibit a satisfactory performance. On the other hand, when each motivation type was examined individually by itself, it was found that intrinsic motivation to know was also indirectly related to grade point average, indicating that the students who relish learning are likely to garner the intellectual advantages of the university as well.
\end{abstract}

Keywords : Academic motivation, academic integration, academic performance, bootstrap mediation

DOI: $10.7176 / \mathrm{JEP} / 10-9-07$

Publication date:March $31^{\text {st }} 2019$

\section{Introduction}

According to Tinto (1993), university students, especially during their first year, may be exposed to frustrations and disillusionments whose intensity and consequences may impair their future expectations. After synthesizing the research on multiple causes of students' abandoning university education, Tinto presented a theory of student departures from universities inspired by the works of Emile Durkheim (1973) and van Gennep (1960). The theory proposes that student departure may serve as a barometer of the social and intellectual health of university life as much as of the students' experiences at the university. The quality of faculty-student interaction and the student's integration into the school were the central factors in student attrition. Tinto's theory encompasses features of retention programs, including the time of college actions and variations in policy necessary for different types of students and universities. The theory suggests that effective retention lies in the institution's commitment to students.

Tinto (1993) argues that if the potential adjustment problems of university students can be detected early by the educational institutions, they can retain students who may otherwise drop out. Such a detection process necessitates methods for assessing the circumstances that bring about students' relinquishing studying, along with the use of such assessment information for developing effective retention programs.

The literature is replete with the works of researchers investigating the extent to which the performance of a student in a university may be predicted using features such as motivation, intellectual powers and demographic characteristics. For example, Liu and Liu (2000) examined the impact of social and academic integration on the satisfaction and retention of students according to the theoretical framework of Tinto. Variables examined included persistence, satisfaction, academic integration, social integration, academic performance, and demographics. Surveys were later matched with students' transcripts and academic records to determine academic status. Data analysis indicated that academic integration, social integration, and academic performance all had positive influences on student satisfaction with social integration being the most influential factor. Overall, this study validated Tinto's theory. Other examples along similar lines may be those of Lai (2011), Dickinson (1995), Cohn, Cohn, Balch, \& Bradley, (2004), Yükseltürk and Bulut, (2007), Robbins et al. (2004), Sackett, Kuncel, Ameson, Cooper, \& Waters (2009).

Although academic performance in high school and university entrance exams are cited as the best predictors of academic performance and securing a degree (Burgette \& Magun-Jackson, 2009; Camara, 2005), it is argued that psychosocial factors also inspire sucessful performance (Kuncel, Hezlet, \& Ones, 2004; Covington, 2000; Daugherty \& Lane, 1999; Poropat, 2009). Among the psychosocial factors, the motivation to achieve has been established to be one of the strongest predictors of academic performance (Deci \& Ryan, 1985; Poropat, 2009; Komarraju, Karau, \& Schmeck, 2005). Although much of the research on students' adaptation to university environment explore the sufficiency of that propensity (Tinto, 1993; Deci \& Ryan, 2000; Gutierrez \& Tomas, 2018; Schunk, 1991; Heiman \& Precel, 2003), such research also points out that a successful adaptation process may lead to successful academic performance (Thang \& Azarina, 2007; Naumann \& Bandalos, 2003; Pascarella, Pierson, Wolniak, \& Terenzini, 2004). It has also been emphasized in similar studies that academic integration may act as a mediating variable between a multiplicity of social factors and academic performance (Soric, Penezic, \& Buric, 2017; Bowman \& Hill, 2011; Caprara, Vecchione, Gerbino, \& Barbaranelli, 2011; Sutton \& Wheatley, 
2003; Pritchard \& Wilson, 2003).

Although the results of the research on the influence of academic motivation and academic integration on academic performance independently have been widely publicized, the mechanics of the collaboration of academic motivation and academic integration to predict academic performance is not thoroughly explored. Hence, it is hoped that this article will fill that gap by ascertaining the extent of the relationship between academic motivation and the psychosocial factors that are mediated by academic integration in explaining performance.

\subsection{Institutional Integration}

The term institutional integration elucidates a student's ability to adapt to educational environments, such as colleges or universities, and to assimilate coursework (Clark, Middleton, Nguyen, \& Zwick, 2014). It is claimed that there are two types of institutional integration: academic and social (Tinto, 1975; Pascarella \& Terenzini, 1980; Astin, 1975; Alkan, 2014; Bonaldo \& Pereira, 2016; Paura \& Arhipova, 2014). Academic integration refers to a student's potential to benefit from educational experiences, which are based on that student's intellectual capacity and cognitive development within an educational institution (Pascarella \& Terenzini, 1980; French \& Oakes, 2004; Araque, Roldan, \& Salguero, 2009). A student's ability to meet the educational institution's specifications and the ability of the institution to fulfill student's educational vision should intersect at some point for an healthy university life (Tinto, 1975; Arulampalam, Naylor, \& Smith, 2005). Hence, the interactions of the student with the faculty, obtaining satisfactory grades and putting the necessary effort into learning constitute the major aspects of academic integration. Social integration, on the other hand, entails social engagement of the student and interactions with other students for developing friendships, participating in clubs and similar organizations, and getting involved with the faculty for social issues such as harassment (Pittman \& Richmond, 2007). Obviously, both academic and social integration embody communications with other students and the faculty. However, contextually, academic integration denotes educational and intellectual pursuits whereas social integration entails psychological and emotional associations.

\subsection{Institutional integration and academic performance}

According to Van Ryzin, Gravely, \& Roseth (2009), a student's adaption to the university is more formative than earlier visions or any other attributions the student bears. Furthermore, it has been established that a student's academic integration will upgrade the student's cognitive development that will result in better and comprehensive consequences such as better grades and higher degrees (Walker, Greene, \& Mansell, 2006; Wentzel \& Caldwell, 1997; Pertegeal-Felices, Castejon-Costa, \& Jimeno-Morenilla, 2014). Although it is covered in literature that academic performance and retention are shaped by both academic and social integration, it is claimed that comparatively academic integration seems to carry more weight than social integration when it comes to attaining educational results (Tinto, 2010; Robbins et al., 2004; McGaha \& Fitzpatrick, 2005; Nicpon et al., 2006). Only in limited number of studies positive relationships have been mentioned between social integration and academic achievements, but social integration may not be enough to secure solid academic performance (Chimka \& Lowe, 2008; Allen, Robbins, Casillas, \& Oh, 2008; Bray, Braxton, \& Sullivan, 1999). In his model, Tinto (1975) argues that a highly socially-integrated member of a university with insufficient academic integration may not be able to graduate as envisioned. In different proportions, perhaps, both are needed.

As has been pointed out above, although most of the research that dealt with social and academic integration attested that academic performance was shaped heavily by academic integration, it might be surmised that by itself, academic integration was a poor predictor (Smith \& Naylor, 2005; Hanushek, Lavy, \& Hitomi, 2008). It has also been pointed out that different types of academic or social integration result in different performances ways (Schaufeli, Martinez, Pinto, Salanova, \& Bakker, 2002). One could also mention cases in which institutional integration was negatively related to university students' GPAs (Organization for economic cooperation and development, 1997), in which non-cognitive indicators were utilized for early identification (West, 1998; Sandler, 2000).

A comparison of different types of educational programs developed to further success of college students through academic and social integration showed that students did not benefit from programs designed to enhance academic integration in terms of improved grade point averages but social integration programs such as general orientation did result in higher GPA (Colquitt, LePine, \& Noe, 2000; Chemers, Hu, \& Garcia, 2001). Such general orientation programs addressed both academic integration and social integration. As can be inferred, what educational programs offer, intellectual expectations, assistance and services and similar aspects constitute the gist of the academic integration and topics such as developing relationships with faculty, securing financial supports, adjusting to university comprise the social integration.

The relationship between GPA and social and academic integration is not stable but varies according to student's background and the associations the student has cultivated (Schmitt, et al., 2009). According to Harakiewicz, Barron, Tauer, and Elliot (2002), students who joined clubs, participated in interest groups such as fraternities, and fostered strong and formal ties with their peers enjoyed high GPAs. On the other hand, the efforts 
of students who adopted informal social ties only led to low GPAs. Strong and formal academic ties with teaching staff yielded better GPAs, especially if academic enrichment programs such as tutoring were pursued by the institution. Even college students with learning disabilities benefit from social and academic integration (DaDeppo, 2009)

\subsection{Academic motivation}

Bandura (1986) defined academic motivation as "people's judgments of their capabilities to organize and execute courses of action required to attain designated types of performances." Those judgments compel an individual to enroll in an educational institution and attain a degree. Although many theories on general motivation have been constructed (Lai, 2011), the Self-Determination Theory (SDT) of Deci and Ryan (1985) has become of the most potent approaches. Many of these theories simply differentiate autonomous behavior, entailing personal intention or choice from controlled behavior, which is conduct carried out unwillingly or out of compliance. However, the SDT is based on a hierarchical model that depicts three types of behavioral motivation, as illustrated in figure 1 (Deci \& Ryan, 2000)

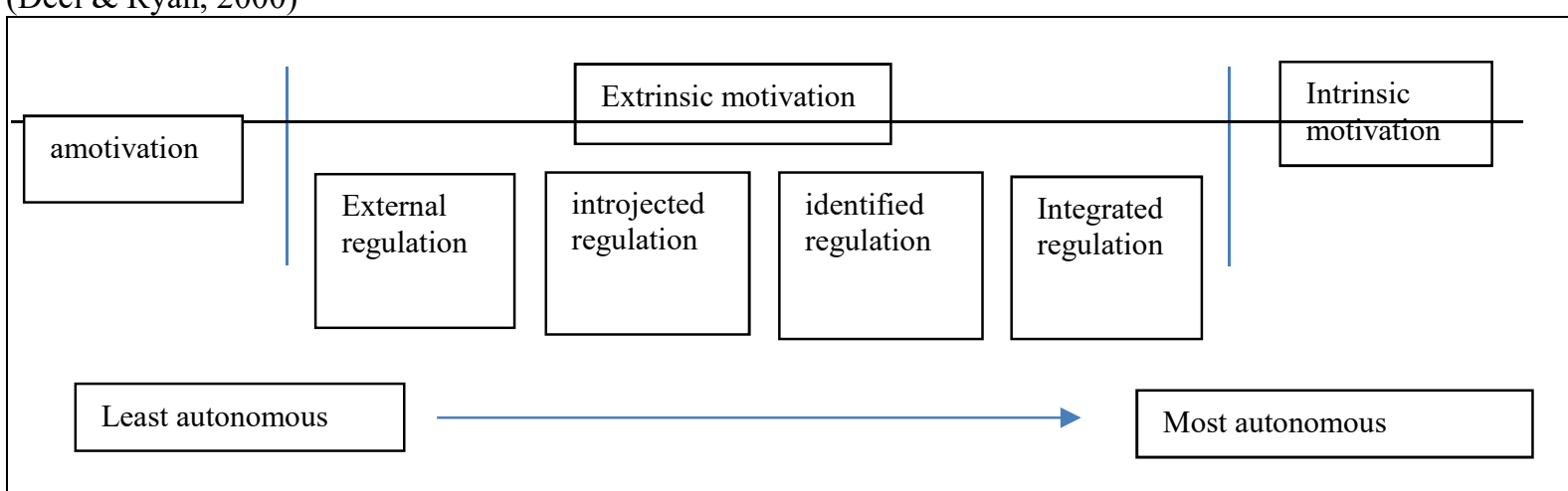

Figure 1 - The self-determination continuum (Ryan \& Deci, 2000)

According to Ryan \& Deci (2000), the self-determination continuum ranges from intrinsic motivation at one end and amotivation at the other with extrinsic motivation lying in between. Extrinsic motivation is divided into four parts - integrated regulation, identified regulation, introjected regulation and external regulation. Intrinsic motivation is driven by a genuine interest in an activity. Intrinsic motivation drives behaviors when behaviors are performed for pleasure or for the sake of enjoyment, such as a student studying for a course he or she really revels in.

Behaviors are induced by extrinsic motivation when coveted gains are the targets, which may be to achieve a goal or collect a reward beyond the activity itself such as a student attending a university, not because the student enjoys learning but because of the expectation of a better position or earning a higher salary. External regulation cover situations in which a person gets involved to obtain an external reward or avoid punishment. A student with a weak average may study for long hours every night to avoid academic suspension. Introjected regulation emerges when the individual behaves in a manner to fulfill personal expectations. In this case, motivation is internalized but the aspect of being engaged for the pleasure of the activity is missing as in the case of an individual venturing an activity just to prove he or she can succeed. Identified regulation materializes when an individual deals conscientiously with a condition that may help him or her, but lacks the authentic satisfaction or pleasure such as a student taking a course that may help him or her understand related material better. Integrated regulation materializes when the individual perceives an activity as being supportive of other values, needs or behaviors such as taking up sports to avoid obesity and/or to stay healthy.

Amotivation is when individuals are not motivated at all because they are neither interested in the activity nor do they perceive being rewarded for their behavior. A student may attend university not because of his or her feeling responsible for the outcome but because of, for example, being coerced by their parents.

Self-determination or autonomous motivations yield desirable results such as deep learning (Deci \& Ryan, 1985; Vansteenkiste, Sierens, Soenens, Luyckx, \& Lens, 2009a), high academic performance, (Vallerand et al., 1992), smoother adjustment (Levesque, Zuelke, Stanek, \& Ryan, 2004) and positive well-being (Boggiano, Flink, Shields, Seelbach, \& Barret, 1993).

STD is amenable to be organized in a variety of forms depending upon context of the study. Some researchers preferred three factor structure using only three motivation types (Komarraju, Karau, \& Schmeck, 2009; Mills \& Blankstein, 2000). Others found a four factor structure more suitable for their purposes (Boggiano A. , Flink, Shields, Seebach, \& Barrett, 1993; Guiffrida, Lynch, Wall, \& Abel, 2013). Modified constructs using Deci and Ryan's approach have also been developed. A scale developed for measuring motivation of students utilizes the three basic intrinsic, extrinsic and amotivation factors of Deci and Ryan (1985) and arrives at a finer result with the addition of a number of factors (Vallerand, Blais, Briere, \& Pelletier, 1989; Vallerand, et al., 1993). Vallerand 
et al. (1989) came up with three marked regulations of extrinsic motivation: external, introjected and identified. Furthermore, three subfactors of intrinsic motivation were also identified: intrinsic motivation to know (IM-toknow), intrinsic motivation toward accomplishments (IM-to-accomplish things) and intrinsic motivation to experience stimulation (IM-to-experience stimulation). The motivation is referred to as IM-to- know when the individual is absorbed in a deed for the primary purpose of gaining knowledge about or investigating something novel. For instance, a student may study simply because he or she may find that subject fascinating. The motivation becomes IM- to- accomplish things when a behavior is performed for the satisfaction of undertaking a task or to feel proficient or to generate something. For example, a student may produce a number of drafts for getting a perfect final result. The motivation is denoted IM-to-experience stimulation whenever the individual deals with an activity that he or she finds stimulating. For example a student may participate an extracurricular activity because he or she may find that activity appealing and inspiring.

\subsection{Academic motivation and academic achievement}

It has been established that academic motivation is one of the most potent predictors of academic achievement (DeBerard, Spielmans, \& Julka, 2004; Gerdes \& Mallinckrodt, 1994; Tross, Harper, Osher, \& Kneidinger, 2000). However, different types of motivation relate to performance in different ways. Some researchers found that students with high levels of intrinsic motivation attained higher grade point averages (Chamorro-Premuzic \& Furnham, 2003; Conrad \& Patry, 2012). However, other researchers did not arrive at this conclusion (DeYoung, Quilty, \& Gray, 2013; Poropat, 2009). In their study, Komarraju and Karau (2005) were able to show the relationship between intrinsic motivation and academic achievement using a three factor model, but a seven factor model indicated that only IM to accomplish predicted performance (Furnham \& Mitchell, 1991). Hulleman, Schrager, Bodmann, \& Harackiewicz (2010) noted that among the three types of intrinsic motivation, only IM to accomplish things provided a positive correlation with GPA.

The results of the studies between external motivation and academic performance were even more mixed. Some researchers did not find any relationship between extrinsic motivation and academic achievement (Paris \& Paris, 2001; Zimmermann \& Moylan, 2009; Vrugt \& Oort, 2008; Valle et al., 2003). Pascarella, Pierson, Wolniak, and Terenzini (2004) suggested that among the first year university students, extrinsic motivation envisaged lower GPAs. The traditions or conventions of communities sometimes can cause university students to respond to external regulation, one of the measures of extrinsic motivation (DeBerard, Spielmans, \& Julka, 2004; Gutierrez \& Tomas, 2018; Pascarella, Pierson, Wolniak, \& Terenzini, 2004).

In general, students who were deficient in academic motivation displayed poor academic performance (Beets \& Lobingier, 2001; Schunk, 1991; Tross, Harper, Osher, \& Kneidinger, 2000). No academic success was predicted for amotivated students during their first year at university (Pritchard \& Wilson, 2003; Komarraju \& Karau, 2008; Clark, Middleton, Nguyen, \& Zwick, 2014; Allen, Robbins, Casillas, \& Oh, 2008).

\subsection{Linking academic motivation with academic integration}

The current study attempts to discern the extent of the relationship between academic motivation and academic integration, although by themselves both academic motivation and academic integration are known to influence academic performance. The studies that explored the manner in which academic motivation and institutional integration jointly predict academic achievement seemed to be hindered by the methodology employed (HazratiViari, Rad, \& Torabi, 2012; Cheng \& Ickes, 2009; Clark \& Scroth, 2010). Those studies appeared to be deficient in their investigation of the relationship between integration and motivation (Chamorro-Premuzic \& Furnham, 2008; Kuncel \& Klieger, 2007). Although Clark and Scroth (2010) and Laidra, Pullman, and Allik (2007) noted that achievement drive and social integration were unrelated ; Cheng \& Ickes (2009) maintained the presence of a negative relationship between the needs for achievement and affiliation, albeit a small one. However, neither of these explored the relationship between academic motivation and academic integration when they acted together. The best evidence for how motivation and integration simultaneously related to academic performance was furnished by Steinmayr and Spinath (2009) and Wagerman and Funder (2007). Both studies arrived at the conclusion that academic performance could be predicted by amotivation, extrinsic motivation and academic integration and therefore established the relationship between academic integration and motivation. As can be expected, amotivation was negatively related to academic integration while intrinsic and extrinsic motivation turned out to be positively related.

In their investigations, Steinmayr, Bipp, and Spinath (2011), Seifert (2004), Walls and Little (2005), and Chapman and Pascarella (1983) maintained that mediational relationships between social elements and academic achievement could be established if the elements of institutional integration, academic motivation and performance were investigated. Therefore, the question of to what extent does academic integration mediate the relationships between academic achievement and academic motivation has become the focal point of this study. Measuring academic motivation using the seven subscales of Vallerand et al. (1993), ascertaining the correlation between academic integration and motivation and depicting the indirect relationships between academic motivation and 
performance via integration are the three aims.

\section{Methodology}

\subsection{Participants}

The participants consisted of 258 undergraduate university students enrolled at various departments of a nonprofit, private university in İstanbul, Turkey in 2017. The ages of the students varied between 18 to 20 and they agreed to participate to the study voluntarily without any expectation of neither credit nor any material benefit. Since the language of instruction is English, the scales used were in English as well. The native language of the students was Turkish and English was their second language with levels ranging from intermediate to advanced. The breakdown according to departments and gender is given in table 1:

Table 1. Breakdown of participants according to gender and department

\begin{tabular}{|c|c|c|c|c|c|c|c|c|c|c|c|c|c|}
\hline Department & \multicolumn{2}{|c|}{ Arts \& Sci. } & \multicolumn{2}{|c|}{ Bus. Adm. } & \multicolumn{2}{|c|}{ Commun. } & \multicolumn{2}{|c|}{ Engineer. } & \multicolumn{2}{|c|}{ Architect. } & \multicolumn{2}{|c|}{ Law } & \multirow[t]{2}{*}{ total } \\
\hline Gender & $\mathrm{M}$ & $\mathrm{F}$ & $\bar{M}$ & $\mathrm{~F}$ & $\bar{M}$ & $\mathrm{~F}$ & $\mathrm{M}$ & $\mathrm{F}$ & $\mathrm{M}$ & $\mathrm{F}$ & $\mathrm{M}$ & $\mathrm{F}$ & \\
\hline Number & 26 & 19 & 25 & 17 & & 21 & 32 & 25 & 19 & 21 & 18 & 15 & \\
\hline Sum $(M+F)$ & \multicolumn{2}{|c|}{45} & \multicolumn{2}{|c|}{42} & \multicolumn{2}{|c|}{41} & \multicolumn{2}{|c|}{57} & \multicolumn{2}{|c|}{40} & \multicolumn{2}{|c|}{33} & 258 \\
\hline$\%$ & \multicolumn{2}{|c|}{17.5} & \multicolumn{2}{|c|}{16.3} & \multicolumn{2}{|c|}{15.9} & \multicolumn{2}{|c|}{22.1} & \multicolumn{2}{|c|}{15.4} & \multicolumn{2}{|c|}{12.8} & 100 \\
\hline
\end{tabular}

$87 \%$ of the students were first-year, $9 \%$ were second and $4 \%$ third-year students.

\subsection{Measures}

\subsubsection{The Institutional Integration Scale (IIS)}

The Institutional Integration Scale (IIS) was conceived and designed to assess Tinto's (1975) theory initially by Pascarella and Terenzini (1980) and it attempts to measure the extent of university students' commitment to education and also to investigate the nature of students' abandoning education. It consists of 30 items spread among 5 subscales. The subscales are peer group interaction (measured by seven items), interactions with faculty (covered with five items), faculty concern for student development and teaching (appraised by five items), academic and intellectual development (judged by seven items) and institutional and goal commitments (depicted by 6 items). This construct was later modified by Fox (1984) and the modified version was utilized in this study. The reliability and discriminant validity of Fox's modified version of the IIS has been established in a number of studies (French \& Oakes, 2004; Peterson, 1993; Baker, Caison, \& Meade, 2007). Cronbach's alphas , ranging from r $=0.76$ to $r=$ 0.84 indicated that all five subscales had good internal consistency. Intercorrelations between subscales corroborated that they were measuring different constructs. All five subscales were administered to the students, however, only the academic and intellectual development subscale was incorporated into this study. The internal consistency for this subscale was $\mathrm{r}=0.74$.

\subsubsection{The Academic Motivation Scale (AMS-C28)}

The intention of the Academic Motivation Scale - college version - 28 questions (AMS-C28) is to ascertain what stimulates students to attend a university (Vallerand et al., 1993; Vallerand et al., 2004). Seven subscales, based on the Self-Determination Theory (STD) of Deci and Ryan (1985), comprise its main structure. Three of these subscales, intrinsic motivation to know (IM to know), intrinsic motivation towards accomplishments (IM to accomplish), and intrinsic motivation to experience stimulation (IM to experience) relate to intrinsic motivation. Three additional subscales, external motivation, introjected motivation, and identified regulation constitute parts of extrinsic motivation. Amotivation is the seventh subscale.

Reliability of the AMS-C28 has been ascertained with Cronbach's measures of internal consistency. Although each subscale contains only four items, Cronbach's alpha indicated that all seven had good internal consistency ranging from $r=0.82$ to $r=0.89$ (Köseoğlu, 2013; Nunnally \& Bernstein, 1994; Vallerand et al., 1992). All subscales used in this study had good internal consistency, with Cronbach's alphas ranging from 0.74 to 0.92 . Construct validity of the AMS-C28 has been corroborated with significant correlations upheld between the seven subfactors (Vallerand et al., 1993), existing measures of motivation, motivational premises and outcomes.

\subsubsection{The Grade Point Average (GPA)}

The GPAs of the participants were obtained from the university's registration office with the students' permission. The first year GPA was calculated by averaging the participants' GPAs. For example, the tests were administered just before the end of the spring semester and the average of the GPAs of the fall and spring semesters of 2017 were taken after the final grades were submitted.

\subsection{The Procedure}

Participants were recruited from different departments as a part of a study related to academic success and university attrition. Self reported data was submitted and the two scales were administered at the end of the spring term of 2017. No objections were raised by the participants to the researcher accessing their academic records. The self-reported data basically covered questions about personality, significance of university and demographic information that might have been relevant to academic performance. Only two of measures, the AMS-C28 and 
the IIS were used for this research. Ethical standards to protect the rights of the participants were observed throughout the study.

\section{Results}

\subsection{The Normal Distribution}

In general, the Normal Theory approach would be the norm when dealing with mediational models (Baron \& Kenny, 1986). For the Normal Theory to hold, the sample size should be as large as possible and the distributions of the mediating and dependent variables should be as near to the normal as possible (Iacobucci, 2008; Shrout \& Bolger, 2002). It turned out, however, neither the data for academic integration, nor the data of the first year GPA were normally distributed in this study. Hence, the bootstrap technique, in which samples are randomly drawn from the original data set and are returned to the original set, appeared to be more adequate as the emerging distributions turn out to be less skewed and kurtotic. (Preacher \& Hayes, 2008). Indirect effects are estimated for the 1500 samples drawn and $95 \%$ confidence intervals were observed to verify whether or not the indirect effects were significant.

\subsection{Regression}

In order to confirm the validity of the results, relevant tests for statistical assumptions for linear regression were carried out on the original data set. First, the question of whether or not the direct effects were moderated by gender was addressed. It was clear that gender did not affect any of the statistical relationships between motivational types or academic achievement and academic integration.

Secondly, analyses of the trends indicated that in all the relationships between motivation types, academic integration and GPA were found to be linear, except one. As can be seen in figure 2, a cubic relationship between IM to accomplish and academic integration was detected. Therefore, the non-linear trends of this variable were incorporated into the mediational models. For students whose IM to accomplish were moderate (scores between 3-5) there was no relationship between IM to accomplish things and academic integration. On the other hand, for students who had either high (scores above 5) or low (below 2) there was a positive relationship between IM to accomplish and academic integration.

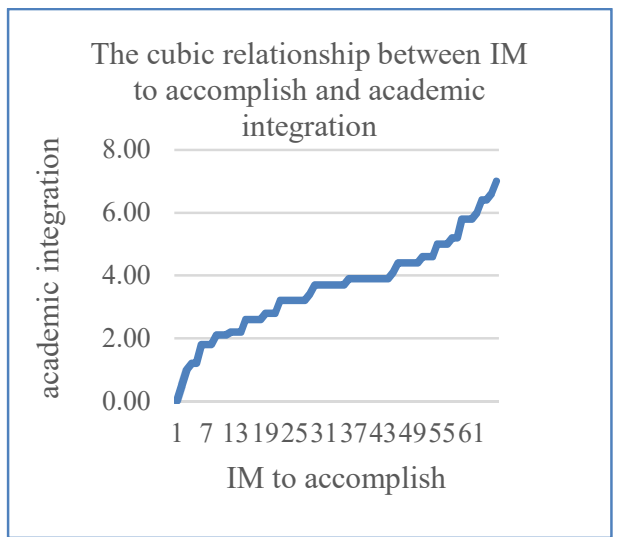

Figure 2 - chart showing the cubic relationship between IM to accomplish and academic integration

Next, each academic motivation type was regressed onto academic integration one by one with ShapiroWilk's test denoting that the residual errors from the regressions were not normally distributed. Then, all academic motivation types were regressed simultaneously onto academic integration with the Shapiro-Wilk's test not yielding a normal distribution for the residual errors. A similar outcome for the regression of academic integration onto GPA was obtained. Fortunately, the bootstrap method tends to reduce the effects of such occurrences (Efron \& Tibshirani, 1993).

Finally, in each regression, it was found that the tolerance and variance inflation factors (VIF) fell within acceptable limits ( tolerance $>0.3$ and VIF $<4$ ). Despite this, as can be seen in table 1 , some of the correlations between seven academic motivations turned out to be high. If all the motivational types are lumped into a single regression model, multicollinearity becomes a concern as each mediation model considers the motivational types probably twice. 
Table 1- Medians, min and max ranges and correlations between academic motivation types, academic integration and the first year GPA

\begin{tabular}{|l|l|l|l|l|l|l|l|l|l|l|l|}
\hline$\#$ & Variable & median & range & 1 & 2 & 3 & 4 & 5 & 6 & 7 & 8 \\
\hline 1 & IM to know & 5.12 & $1.00-8.00$ & & & & & & & & \\
\hline 2 & IM to accomplish & 4.65 & $1.65-6.95$ & 0.74 & & & & & & & \\
\hline 3 & IM to experience & 3.25 & $1.20-6.80$ & 0.79 & 0.62 & & & & & & \\
\hline 4 & Identified regulation & 5.95 & $3.20-7.45$ & 0.61 & 0.46 & 0.32 & & & & & \\
\hline 5 & Introjected regulation & 5.35 & $1.20-7.60$ & 0.52 & 0.75 & 0.38 & 0.47 & & & & \\
\hline 6 & External regulation & 6.30 & $2.45-7.90$ & 0.41 & 0.38 & 0.16 & 0.61 & 0.29 & & & \\
\hline 7 & amotivation & 1.10 & $1.00-4.75$ & -0.37 & -0.33 & -0.26 & -0.39 & 0 & -0.22 & & \\
\hline 8 & Academic integration & 3.90 & $2.35-5.60$ & 0.45 & 0.37 & 0.25 & 0.22 & 0.22 & 0.09 & -0.15 & \\
\hline 9 & First year GPA & 3.25 & $1.36-4.00$ & 0.15 & 0.07 & -0.16 & 0.20 & -0.25 & 0.04 & -0.25 & 0.45 \\
\hline
\end{tabular}

Note - since some of the distributions were normal and some of the relationships were curvilinear, medians were reported instead of means and correlations were computed using Spearman's Correlation. Correlations are represented as effect sizes.

\subsection{Mediational Analyses}

For each of the seven types of academic motivation, 1500 bootstrapped samples of size $\mathrm{N}=258$ were computed in order to estimate the indirect effect of each of the seven types of academic motivation on GPA without taking into consideration the contribution of the other motivation types, using the macro INDIRECT for SPSS of (Preacher \& Hayes, 2008). The SPSS and SAS macro command sets may be accessed online through www.quantpsy.org. As can be seen in table 2, it was found that the academic integration mediated the relationship between two of the seven types of academic motivation and the GPA.

Table 2 - Indirect effects of motivation on GPA

\begin{tabular}{|l|l|l|l|l|l|l|}
\hline $\begin{array}{l}\text { Independent } \\
\text { variable }\end{array}$ & \multicolumn{2}{l}{ Without controlling for other IVs } & \multicolumn{2}{l|}{ Controlling for other IVs } \\
\hline & $\begin{array}{l}\text { Mean } \\
\text { indirect } \\
\text { estimate } \\
(\mathrm{ab})\end{array}$ & SE & $95 \%$ CI & $\begin{array}{l}\text { Mean } \\
\text { indirect } \\
\text { estimate } \\
(\mathrm{ab})\end{array}$ & SE & $95 \%$ CI \\
\hline IM to know & 0.064 & 0.036 & $0.028 ; 0.126$ & 0.06 & 0.051 & $-0.040 ; 0.245$ \\
\hline IM to accomplish $(*)$ & 0.006 & 0.007 & $0.003 ; 0.031$ & 0.007 & 0.005 & $0.003 ; 0.026$ \\
\hline IM to experience & 0.038 & 0.034 & $-0.015 ; 0.08$ & -0.036 & 0.034 & $-0.073 ;-0.026$ \\
\hline Identified regulation & 0.050 & 0.041 & $-0.003 ; 0.135$ & -.008 & 0.04 & $-0.071 ; 0.074$ \\
\hline $\begin{array}{l}\text { Introjected } \\
\text { regulation }\end{array}$ & 0.014 & 0.028 & $-0.007 ; 0.075$ & -0.018 & 0.035 & $-0.090 ; 0.032$ \\
\hline External regulation & 0.018 & 0.029 & $-0.034 ; 0.085$ & -0.007 & 0.034 & $-0.064 ; 0.056$ \\
\hline amotivation & -0.085 & 0.078 & $-0.287 ; 0.004$ & -0.005 & 0.066 & $-0.183 ; 0.058$ \\
\hline
\end{tabular}

(*) This model includes linear, quadratic and cubic terms for the independent variable. Estimates in bold are statistically significant.

As illustrated in table 2, the means of the 95\% confidence intervals for the indirect estimates (ab) suggest that IM to know and IM to accomplish are indirectly related to first year GPA through academic integration. In other words, the non-linear relationship between IM to accomplish and the first year GPA are mediated by academic integration.

Figures 3 and 4 below illustrate the direct and indirect effects.

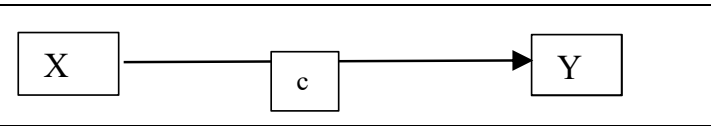

Figure 3-direct effect - X affects Y 


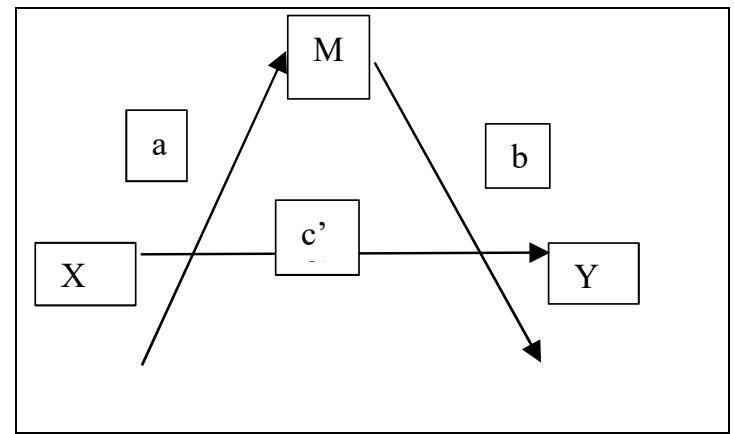

Figure $4-\mathrm{X}$ exerts an indirect effect on $\mathrm{Y}$ through the mediator $\mathrm{M}$.

To explain the correlations between seven types of academic motivation, the PROCESS macro of Hayes (2017) was used to compute bootstrapped path analyses. Results of the analyses were expected to provide an estimate of the indirect effect of academic motivation on GPA. On the other hand, as displayed in table 2, academic integration only mediated the relationship between IM to accomplish and GPA. The relationships between IM to accomplish, academic integration and GPA were similar to those attained when investigating the motivation types independent of each other.

\section{Conclusions \\ 4.1. Findings}

The key finding of this study is that academic integration may mediate the relationship between some types of intrinsic academic motivation and academic achievement. Students who enroll in a university for the satisfaction of attaining academic goals tend to believe that institutions of higher education may help them develop intellectually. That belief drives them to perform well academically. While this is valid for individuals who are strongly driven to accomplish, it does not hold for those who are less inspired by their achievements. It is possible to state that the students who drive little internal satisfaction from university education will attain little cognitive accomplishment for their efforts and may face failure. There is also evidence that those attending a university because they enjoy learning new things are inclined to be convinced that the universities are replete with newest things and they are prepared to learn all about them. Despite the fact that this mediational relationship may be stronger than the indirect effect IM-to-accomplish has on GPA, it seems to be unreliable and may not predict GPA adequately. The indirect relationship between amotivation and GPA is also interesting in the sense that it points out the presence of a certain segment of the student body who believe that there are no intellectual benefits for attending a university. This probably is a result of the number of people in the sample who chose to attend university not because they were stimulated academically. The statistical estimates for this type of relationship were high, and so were their variability.

Some strong correlations between the seven motivational types were found. This, on the other hand, seemed to have made no influence on how each motivation type modified academic performance through academic integration. As can be seen in table 1, the three items of intrinsic motivation correlated well with each other. Furthermore, it can be deduced from the same table that the three items of extrinsic motivations correlated well with each other as well. Thus, it can be surmised that these were distinctly different types of academic motivation. In most analyses, the same effect was detected whenever each motivational type was tested independently of the others. The only exception was the indirect relationship between IM to know and academic performance as measured by GPA. The strong association between IM-to-know and other types of intrinsic and extrinsic motivation could be inferred as the reason behind this.

\subsection{Inferences}

IM-to-accomplish was the only motivation type that influenced academic performance through academic integration. IM-to-know and IM-to-experience stimulation were also found to be linked to academic integration. Hence, it is reasonable to infer that intrinsic motivation predicts students' capacity to conform to the scholarly demands of university life. On the other hand, identified regulation and amotivation may not predict integration. It may be inferred that those two may be useful to academic counselors for identifying students who may have to resolve complications while adjusting to university life. By perceiving how academic motivation impacts institutional integration, the academic advisors can guide students suffering from frustration and disillusionment to participate in programs that may help them.

Academic integration was positively correlated with first year GPA $(r=0.42, p=0.007)$ no matter what the indirect relationships between academic motivation and academic achievement may be. It may also be inferred that developing programs be universities that show students how to get accustomed to university life both socially and academically as those institutions recognize the significance of promoting a successful educational life (Taylor 
et al., 2014).

\subsection{Integration}

The extent of the students' satisfaction with their with academic integration depends upon the extent of their satisfaction with their academic experiences, which, in turn, depends on to the extent of their being able to meet academic standards. Many of the students who enrolled in universities with low standards of admission are illprepared for the intensity of work expected of them (Levesque, Zuelke, Stanek, \& Ryan, 2004). Academic integration will be realized when the student is able to respond to the university's academic expectations and when the university delivers student's educational needs (Tinto, 1993). If a student is unable to succeed in coursework despite his or her best efforts, then the intellectual integration will not be realized due to insufficient level of cognitive capacity. If a student does not have the opportunities to learn skills necessary for a certain career path, then the intellectual integration will not be realized due to due to lack of prospects. If both needs are met, then the student will be committed to the university through intellectual integration.

Obviously, the university staff alone cannot be held responsible for the adaptation of a student. However, they can guide the students to achieve academic success and encourage them to strive for academic success through integration. Some institutions offer mentoring, tutoring, and honors programs to stimulate a student's urge to learn (Gerdes \& Mallinckrodt, 1994). It appears that developing and supporting academic programs that lend a helping hand to struggling students will impel them to realize their academic goals and also meet the demands of instructors. Furthermore, as Otis, Grouzet, and Pelletier (2005) and Koestner, Otis, Powers, Pelletier, and Gagnon (2008) claim, there is a fundamental relationship between the interaction with faculty that stimulates academic integration and the quality and quantity of effort a student exerts. Faculty can provide academic integration by generating relevant intellectual pursuits and creating classroom environments that facilitate students' contributions and participations.

\subsection{Limitations}

Two limitations of this study are worth mentioning. One of them is sample size and the second generalizations.

Firstly, it should be acknowledged that a small sample size is a potential problem that may affect both the statistical conclusion validity and the external validity of the results. Employing the bootstrap method mitigates the risks of low statistical power and violation of statistical assumptions. However, it could not ensure that the sample reflected the behavior of all first-year university students and prevented the investigation of other potential moderating factors. A more diverse sample might have been conducive to more transparent outcomes. It should also be noted that the inclusion of upper class students into the sample might have produced different results.

The second aspect is related to the generalizability and validity of the measures utilized for assessing academic motivation and institutional integration. As has been emphasized in the introduction, the aim of administering suitable versions of these scales is to detect early potential adjustment problems and increase the retention of students who might otherwise drop out.

The psychometric evidence for the validity and reliability of the AMS-C28 proved its suitability for studies of this type (Vallerand et al., 1993; Vallerand et al.,1992). Other researchers have found that the seven factor structure holds across a variety of samples of university students (Utvaer \& Haugan, 2016; Orsiniet al., 2015). However, as has been underlined in the literature review, other measures of academic motivation have been designed and used successfully. A three factor model that only assessed intrinsic motivation, extrinsic motivation and amotivation such as that utilized by Komarraju, Karau, \& Schmeck (2009) or a four factor model that evaluated intrinsic motivation, identified regulation external regulation and amotivation such as that used by Stover, de la Iglesia, Baubeta, \& Liporace (2012) could have provided stronger indirect effects.

Similar to the case of AMS-C28, scales besides that of Pascarella \& Terenzini (1980) are available for assessing IIS such as that of French and Oakes (2004) and Baker and Siryk (1999). French and Oakes (2004) claimed that the original construct of Pascarella and Terenzini (1980) measured only two subfactors, faculty and student, and not five and they modified their version accordingly. Another construct by Baker and Siryk (1999), titled the SACQ - Student Adaptation to College Questionnaire- is 67-item self-report inventory that assesses overall adjustment to college, as well as adjustment in four specific areas academic adjustment, personal-emotional adjustment, social adjustment, attachment to the institution. Obviously, different scales instigate different results.

\section{Bibliography}

Alkan, A. (2014). Humor, Loneliness and acceptance: predictors of university drop-out intentions. Procedia social and behavioral sciences, 152, 1079- 1086.

Allen, J., Robbins, S., Casillas, A., \& Oh, I. (2008). Third year college retention and transfer: effects of academic performance, motivation and social connectedness. Research in higher education, 49(7), 647-664.

Araque, F., Roldan, C., \& Salguero, A. (2009). Factors influencing university dropout rates . Computers and educations, 53(3), 563-574. 
Arulampalam, W., Naylor, R., \& Smith, J. (2005). Effects of in-class variation and student rank on the probabbility of withdrawal: cross section and time series analysis for UK university students. Economics of Education Review, 24(3), 251-262.

Astin, A. (1975). Preventing students from dropping out. San Fransisco, CA: Jossey-Bass.

Baker, B., Caison, A., \& Meade, A. (2007). Assessing gender related differential item functioning and predictive validity with the institutional integration scale. Educational and psychological measurement, 69(3), 545-559.

Baker, R., \& Siryk, B. (1999). SACQ Student adaptation to college questionnaire (2nd ed.). Los Angeles, CA: Western Psychological services.

Bandura, A. (1986). Social foundations of thought and action: a social cognitive theory. Englewood Cliffs, NJ: Prentice-hall.

Bargh, J., \& McKenna, K. (2004). The Internet and social life . Annual Review of Psychology, 55, 573-590.

Baron, R., \& Kenny, D. (1986). The moderator - mediator variable distinction in social psychological research: conceptual, strategic and statistical considerations. Journal of personality and social psychology, 51, 11731182.

Beets, D., \& Lobingier, P. (2001). Pedagogical techniques: student performance and preferences. Journal of education for business, 76, 231-235.

Boggiano, A., Flink, C., Shields, A., Seebach, A., \& Barrett, M. (1993). Use of techniques promoting students' self determination: effects on students' analytic problem-solving skills. Motivation and emotion, 17(4), 319336.

Boggiano, A., Flink, C., Shields, A., Seelbach, A., \& Barret, M. (1993). Use of techniques promoting students' self-determination : effects on students' analystic problem-solving skills. Motivation and emotion, 17(4), 319336.

Bonaldo, L., \& Pereira, L. (2016). Drop-out: Demogrphic profile of Brazilain university students. Procedia-cocial and behavioral sciences, 228, 138-143.

Bowman, N., \& Hill, P. (2011). Measuring how college affects students: social desirability and other potential biases in college student self-reported gains. Validity and limitations of college student self-report data . (S. Herzog, \& N. Bowman, Eds.) San Fransisco, CA: Jossey-Bass.

Bray, N., Braxton, J., \& Sullivan, A. (1999). The influence of stress-related coping strategies on college student departure decisions. Journal lof college student development, 40(6), 645-657.

Burgette, J., \& Magun-Jackson, S. (2009). Freshman orientation, persistence and achievement: a longitudinal analysis. journal of colleg retention, theory and practice, 10(3), 235-263.

Camara, W. (2005). Broadening predictors of college success. Choosing students: higher education admissions tools for the 21st century. (W. Camara, \& E. Kimmel, Eds.) Mahwah, NJ: Erlbaum.

Caprara, G., Vecchione, .., Gerbino, M., \& Barbaranelli, C. (2011). The contribution of personality traits and self efficacy belifes to academic achievement: a longitudinal study . British journal of educational psychology, 81, 78-96. doi:http://dx.doi.org/10.1348/2044-8279.002004

Chamorro-Premuzic, T., \& Furnham, A. (2003). Personality predicts academic performance: evidence from two longitudinal university samples. Journal of research in personality, 37, 319-338.

Chamorro-Premuzic, T., \& Furnham, A. (2008). Personality, intelligence and approaches to learning as predictors of academic performance. 44, 1596-1603.

Chapman, D., \& Pascarella, E. (1983). Predictors of academic and social integration of college students . Research in higher education, 19(3), 295-322.

Chemers, M., Hu, L., \& Garcia, B. (2001). Academic self-efficacy and first year college student performance and adjustment. Journal of educational psychology, 93, 55-64.

Cheng, W., \& Ickes, W. (2009). Conscientiousness and self-motivation as mutually compensatory predictors of university level GPA . Personality and individual differences, 47, 817-822.

Chimka, J., \& Lowe, L. (2008). Interaction and survival analysis of graduation data. Educational Research and review, 3(1), 29-32.

Clark, M., \& Scroth, C. (2010). Examining relationships between academic motivation and personality among college students . Leaning and i,ndividual differences, 20, 19-24.

Clark, M., Middleton, S., Nguyen, D., \& Zwick, L. (2014). Mediating relationships between academic motivation, academic integration and academic performance. Learning and individual differences, 33, 30-38.

Cohn, E., Cohn, S., Balch, D., \& Bradley, J. (2004). Determinants of undergraduate GPAs: SAT scores, highschool GPA and high- school rank. Economics of education review, 23, 577-586. doi:http://dx.doi.org/10.1016/j.econedurev.2004.01.001

Colquitt, J., LePine, J., \& Noe, R. (2000). Toward an integrative theory of training motivation: a meta-analystic path analysis of 20 yeras of research. Journal of applied psychology, 85, 678-707.

Conrad, A., \& Patry, M. (2012). Conscientiousness and academic performance : a mediational analysis . International journal for the scholarship of teaching and learning , 6(1), 1-14. 
Covington, M. (2000). Goal theory, motivation, and school achievement: an integrative review. Annual review of pschology, 51, 171-200.

DaDeppo, L. (2009). Integration factors related to the academic success and intent to persist of coillege students with learning disabilities. Learning disabilities research and practice, 24(3), 122-131.

Daugherty, T., \& Lane, E. (1999). A longitudinal study of academic and social preditors of college attrition. Social behavior and personality, 27, 355-362.

DeBerard, M., Spielmans, G., \& Julka, D. (2004). Predictors of academic achievement and retention among college freshmen: a longitudinal study. College student journal, 38(1), 66-80.

Deci, E., \& Ryan, R. (1985). Intrinsic motivation and self determination of human behavior. New York: Plenum.

Deci, E., \& Ryan, R. (2000). The "what " and "why" of goal pursuits: human needs and the self-determination behavior . Psychological inquiry, 11, 227-268.

DeYoung, C., Quilty, L., \& Gray, J. (2013). Openness to experience, intellect and cognitive ability. Journal of personality assessment, 96(1), 46-52.

Dickinson, L. (1995). Autonomy and Motivation: a literature review. System, 23(2), 164-174.

Durkheim, E. (1973). Morality and society. Chicago, IL: University of Chicago.

Efron, B., \& Tibshirani, R. (1993). An introduction to bootstrap. Boca Raton, FL: Chapman \& Hall.

Erten, H. (2014). Interaction between academic motivation and student teachers' academic achievement. Procediasocial and behavioral sciences, 152, 173-178.

Fox, R. (1984). Reliability and discriminant validty of institutional integration scales for disadvantaged college students . Educational psychological measurement , 44, 1951-1057.

French, B., \& Oakes, W. (2004). Reliability and validity evidence for the institutional integration. Educational and psychological measurement, 64(1), 88-98.

Furnham, A., \& Mitchell, J. (1991). Personality, needs, social skills and academic achievement: a longitudinal study. Personality and individual differences, 12, 1067-1073.

Gerdes, H., \& Mallinckrodt, B. (1994). Emotional, social and academic adjustment of college students: a longitudinal study of retention. Journal of counselling and development, 72, 281-288.

Guiffrida, D., Lynch, M., Wall, A., \& Abel, D. (2013). Do reasons for attending college affect academic outcomes? A test of a motivational model from a self-determination perspective . Journal of college student development, 54(2), 121-139.

Gutierrez, M., \& Tomas, J. (2018). Motivational class climate, motivation and academic success in university students. Revista de Psicodidactica, 23(2), 94-101.

Hanushek, E., Lavy, V., \& Hitomi, K. (2008). Do students care about school quality? Determinants of drop-out bevavior in devloping countries. 2(1), 69-105.

Harakiewicz, J., Barron, K., Tauer, J., \& Elliot, A. (2002). Prediting success in college: a longititudinal study of achievement goals mand ability measures as predictors of interest and performance from freshman year through graduation. Journal of educational psychology, 94, 562-575.

Hayes, A. (2017). Introduction to mediation, moderation and conditional process analysis. New York, NY: Guilford press.

Hazrati-Viari, A., Rad, A. T., \& Torabi, S. (2012). The effect of personality traits on academic performance: the mediating role of academic motivation. Procedia- social and behavioral sciences, 32, 367-371.

Heiman, T., \& Precel, K. (2003). Students with learning disabilities in higher education: an academic strategies profile. Journal of learning disabilities , 36, 248-258.

Hulleman, C., Schrager, S., Bodmann, S., \& Harackiewicz, J. (2010). A meta analytic review of achievement goal measures: different labels for the same constructs or different constructs with similar labels? Psychological bulletin , 136(3), 422-449.

Iacobucci, D. (2008). Mediation Analysis (quantitative analysis in social sciences). Thousand Oaks, CA: Sage.

Köseoğlu, Y. (2013). Academic motivations of the first year university students and the self-determination theory. Educational research and reviews , 8(8), 418-424.

Koestner, R., Otis, N., Powers, T., Pelletier, I., \& Gagnon, H. (2008). Autonomous motivation, controlled motivation, and goal progress. Journal of personality, 76, 1201-1230.

Komarraju, M., \& Karau, S. (2005). the relationship between the big five personality traits and academic motivation. Personality and individual differences , 39, 557-567.

Komarraju, M., \& Karau, S. (2008). Relationships between perceived value of instructional techniques and academic motivation. Journal of instructional psychology, 35(1), 70-82.

Komarraju, M., Karau, S., \& Schmeck, R. (2009). Role of the big five personality traits in predicting college students' academic motivation and achievement. Learning and individual differences, 19, 47-52.

Kuncel, N., \& Klieger, D. (2007). Application patterns when applicants know the odds: implications for selection research and practice. Journal of applied psychology, 92, 586-593.

Kuncel, N., Hezlet, S., \& Ones, D. (2004). Academic performance, career potential, creativity, and job 
performance: can one construct predict them all. Journal of personality and social psychology, 86, 148-161.

Lai, E. R. (2011). Motivation: a literature review. New York: Pearson.

Laidra, ,. K., Pullman, H., \& Allik, J. (2007). Personality and intyelligence as predictors of academic achievement: a cross-sectional study from elementary to secondary school. Personality and individual differences, 42, 441451.

Levesque, C., Zuelke, A., Stanek, L., \& Ryan, R. (2004). Autonomy and competence in German and American university students: a comparative study based on self-determination theory. Journal of educational psychology, 68-84.

Liu, R., \& Liu, E. (2000). Institutional integration : an analysis of Tinto's theory. Annual forum of the association for institutional research. Institute of educational sciences.

McGaha, V., \& Fitzpatrick, J. (2005). Personal and social contributers to dropout risk for undergraduate students. College student journal, 39(2), 287-297.

Mills, J., \& Blankstein, K. (2000). Perfectionism, intrinsic vs. extrinsic motivation, and motivated strategies for learning. Personality and individual differences, 29, 1191-1204.

Naumann, W., \& Bandalos, D. G. (2003). 1dentifying variables that predict college success for first year students . Journal of college admission, 181, 4-9.

Nicpon, M., Huser, L., Blanks, E., Sollenberger, S., Befort, C., \& Robinson-Kurpius, S. (2006). The relationship of loneliness and social support with college freshmen's academic performance and persistence . Journal of college student retention:research, theory and practice , 8(3), 345-358.

Nunnally, J., \& Bernstein, I. (1994). Psychometric theory (3 rd edition). New York, NY: McGraw-Hill.

Organization for economic cooperation and development. (1997). Diversity in the initial experiences of Australian undergraduates. Thematic review of the first years of tertiary education in Australia. Department of employment, education, training and youth affairs . Retrieved from www.deetya.gov.au/divisions/hed/operations/theme.htm .

Orsini, C., Binnic, V., Evans, P., Ledezmo, P., Fuentes, F., \& Villegas, M. (2015). Psychometric validation of the academic motivation scale ina dental student sample. Journal of dental education, 79(8), 971-981.

Otis, N., Grouzet, F., \& Pelletier, L. (2005). Latent motivational change in an academic setting: a three year longitudinal study. Journal of educational psychology, 97, 170-183.

Paris, S., \& Paris, A. (2001). Classroom applications of research on self regulated learning . Educational psychologist, 36(2), 89-101.

Pascarella, E., \& Terenzini, P. (1980). Predicting freshman persistence and voluntary dropout decisions from a theoretical model. Journal of higher education, 51, 60-75.

Pascarella, E., \& Terenzini, P. (1983). Prediciting voluntary freshman year persistence/withdrawal behavior in a residential university: A path analytic of Tinto's model. Journal of educational psychology, 75, 215-226.

Pascarella, E., Pierson, C., Wolniak, G., \& Terenzini, P. (2004). First generation students : additional evidence on college experiences and outcomes. The journal of higher education, 75(3), 249-284.

Paura, L., \& Arhipova, I. (2014). Cause analysis of students' drop-out rate in higher education study program. Procedia-social and behavioral sciences, 109, 1282-1286.

Pertegeal-Felices, M., Castejon-Costa, J., \& Jimeno-Morenilla, A. (2014). Differences between personal, social and emotional profiles of teaching and computer engineering professionals and students. Studies in higher education, 39(7), 1185-1201.

Peterson, S. (1993). Career decision making self-efficiency and institutional integration of unprepred college students . Research in higher education, 34(6), 659-685.

Pittman, L., \& Richmond, A. (2007). Academic and psychological functioning in late adolescence: The importance of school belonging. The journal of experimental education, 75(4), 270-290.

Poropat, A. (2009). A Meta-analysis of the five factor model of personality and academic performance. Psychological bulletin , 135, 322-338. doi:http://dx.doi.org/10.1037/a0014996

Preacher, K., \& Hayes, A. (2008). Asymtotic and resampling strategies for assessing and comparing indirect effects in multiple mediator models. Behavior research methods , 40, 870-891.

Pritchard, M., \& Wilson, G. (2003). Using emotional and socail factors to predict student success. Journal of college student development, 44, 18-28.

Robbins, S., Lauver, K., Le, H., Davis, D., Langley, R., \& Carlstron, A. (2004). Do psycho-social and study skill factors predict college outcomes. Psychological bulletin, 130, 261-288. doi:http://dx.doi.org/10.1037/00332909.130.2.261

Ryan, R., \& Deci, E. (2000). Intrinsic and extrinsic motivations: classic definitions and new directions. Contemporary educational psychology, 25, 54-67.

Sackett, P., Kuncel, N., Ameson, J., Cooper, S., \& Waters, S. (2009). Does socioeconomic status explain the relationship between admissions tests and post secondaty academic performance. Psychological bulletin, 135, 1-22. doi:http://dx.doi.org/10.1037/a0013978 
Sandler, M. (2000). Caree decision-makjing self-efficay, perceived stress, and an integrated model of student persisternce: a structural model of finances, attitudes, behavior and career development. Research in higher education, 41, 537-580.

Schaufeli, W., Martinez, I., Pinto, A., Salanova, M., \& Bakker, A. (2002). Burnout and engagement in university students : a cross-national study. Journal of cross cultural psychology, 33(5), 464-481.

Schmitt, N., Keeney, J., Oswald, F., Pleskac, T., Billington, A., Sinha, R., \& Zorzie, M. (2009). Prediction of 4 year college student performance using cognitive and noncognitive predictors and the impact on demographic status of admitted students. Journal of applied psychology, 94(6), 1479-1497.

Schunk, D. (1991). Self-efficacy and academic motivation. Educational psychologist, 26, 207-231.

Seifert, T. (2004). Understanding student motivation. Educational research, 46(2), 137-149.

Shrout, P., \& Bolger, N. (2002). Mediation in experimental and non experimental studies: new procedures and recommendations. Psychological methods, 7, 422-445.

Smith, J., \& Naylor, R. (2005). Schooling effects on subsequent university performance: evidence for the UK university population. Economic of education review, 24(5), 249-262.

Soric, I., Penezic, Z., \& Buric, I. (2017). The big five personality traits, goal orientations, anad academic achievement. Learning and individual differences, 54, 126-134.

Spar, D. (2001). Ruling the Waves: Cycles of Discovery, Chaos and Wealth from the compass to the Internet. New York: Harcourt.

Steinmayr, R., \& Spinath, B. (2009). The importance of motivation as a predictor of school achievemenet. Learning and individual differences, 19, 80-90.

Steinmayr, R., Bipp, T., \& Spinath, B. (2011). Goal orientations predict academic performance beyond intelligence and personality. Learning and individual differences , 21(2), 196-200.

Stover, J., de la Iglesia, G., Baubeta, A., \& Liporace, M. (2012). Academic motivation scale: adaptation and psychometric analyses for high school and college students. Psychology research and behavior management, $5,71-83$

Sutton, R., \& Wheatley, K. (2003). Teachers' emotions and teaching : a review of the literature and directions for future research. Educational psychology review, 15, 327-358.

Taylor, G., Jungert, T., Mageau, G., Schattke, K., Dedic, H., Rosenfield, S., \& Koestner, R. (2014). A selfdetermination theory approach to predicting achool achievement over time: the unique role of intrinsic motivation. Contemporary educational psychology, 39, 342-358.

Thang, S., \& Azarina, A. (2007). Investigating readiness for autonomy: a comparison of Malaysian ESL undergraduates of three public universities. Reflections on English Language Teaching, 6(1), 1-18.

Tinto, V. (1975). Dropout from higher education: a theoretical synthesis of recent research. Review of educational research, 45, 89-125.

Tinto, V. (1993). Leaving college: rethinking the causes and cures of students attrition . Chicago, IL: University of Chicago press.

Tinto, V. (2010). From Theory to action: exploring the institutional conditions for student retention. In Higher education: handbook of theory and research. Netherlands: Springer.

Tross, S., Harper, J., Osher, L., \& Kneidinger, L. (2000). Not just the usual cast of characters: using personality to predict college performance and retention. Journal of college student development, 41, 323-334.

Utvaer, B., \& Haugan, G. (2016). Academic motivation scale, dimensionality, reliability and constant validity among vocational students . Journal of vocational education and training, 6(7), 17-45.

Valle, A., Cabanach, R., Nunez, J., Gonzalez-Pienda, J., Rodriguez, S., \& Pineiro, I. (2003). Cognitive, motivational, and volitional dimensions of learning : an emperical test of a hypothetical model. Research in higher education, 44(5), 557-580.

Vallerand, R., Blais, M., Briere, ,., \& Pelletier, L. (1989). Construction and validation of the motivation toward educational scale . Canadian journal of bahavioral sciences, 21(3), 323-349.

Vallerand, R., Pelletier, L., Blais, M., Briere, N., Senecal, C., \& Vallieres, E. (1992). The academic motivation scale: a measure of intrinsic, extrinsic and amotivation in education. Educational and psychological measurement, 1003-1017.

Vallerand, R., Pelletier, L., Blais, M., Briere, N., Senecal, C., \& Vallieres, E. (2004). The academic motivation scale (AMS -C28) College Version. Retrieved May 2017, from http://www.er.uqam.ca/nobel/r26710/LRCS/echelles_en.htm.

Vallerand, R., PelletierL.G., Blais, M., Briere, N., Senecal, C., \& Vallieres, E. (1993). The academic motivation scale : a measure of intrinsic, extrinsic, and amotivation in education. Educational and psychological measurement, 52, 1003-1017.

van Gennep, A. (1960). Rites of passage . Chicago, IL: University of Chicago.

Van Ryzin, M., Gravely, A., \& Roseth, C. (2009). Autonomy, belongingness and engagement in school as contributors to adolescent psychological well-being. Journal of youth and adolescence, 38(1), 1-12. 
Vansteenkiste, M., Sierens, E., Soenens, B., Luyckx, K., \& Lens, W. (2009a). Motivational profiles from a selfdetermination perspective: the quality of motivation matters. Journal of educational psychology, 101, 671688.

Vrugt, A., \& Oort, F. (2008). Metacognition, achievement and goals, study strategies and academic achievement: pathways to achievement. Metacognition and learning, 30, 123-146.

Wagerman, S., \& Funder, D. (2007). Acquaintance reports of personality and academic achievement: a case for conscientiousness. Journal of research in personality, 41, 221-229.

Walker, C., Greene, B., \& Mansell, R. (2006). Identification with academics, intrinsic/extrinsic motivation, and self-efficacy as predictors of cognitive engagement. Learning and individual differences, 16(1), 1-12.

Walls, T., \& Little, T. (2005). Relations among personal agency, motivation, and school adjustment in early adolescence. Journal lof educational psychology, 97, 23-31.

Wentzel, K., \& Caldwell, K. (1997). Friendships, peer acceptance, and group membership: relations to academic achievement in middle school. Child development, 68, 1198-1209.

West, R. (1998). Learning for life : higher education review - final report. Department of employment, education, training and youth affairs. Retrieved from www.deetya.gov.au/divisions/hed/hereview/execsum1.htm.

Yükseltürk, E., \& Bulut, S. (2007). Predictors for student success in an online course. Educational technology and scoeity, 10(2), 71-83.

Zimmermann, B., \& Moylan, A. (2009). Self Regulation: where meta cognition and motivation intersect. Handbook of metacognition in education, 200-317. (D. Hacker, J. Dunlosky, \& A. Graesser, Eds.) New York, NY: Routledge. 